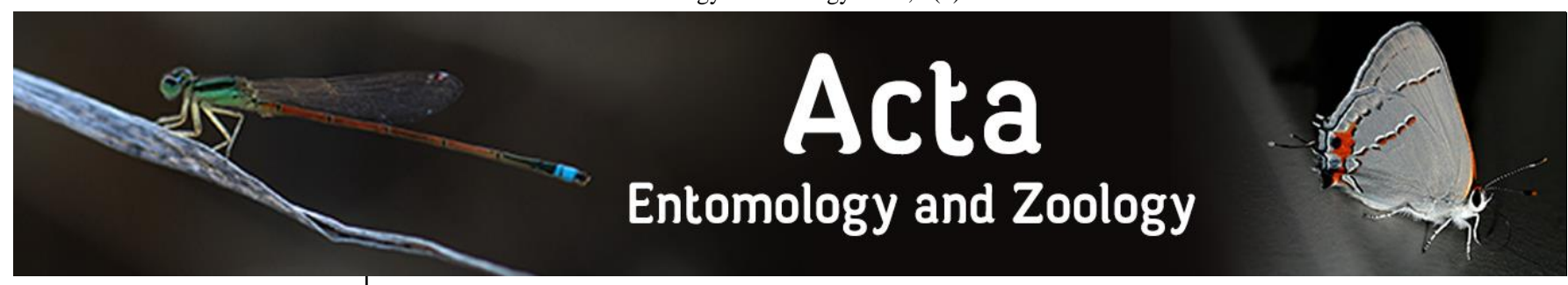

E-ISSN: 2708-0021 P-ISSN: 2708-0013 www.actajournal.com AEZ 2020; 1(1): 54-57 Received: 02-11-2019 Accepted: 30-12-2019

Mahran Zeity

Latakia Center for Scientific Agricultural Research, General Commission for Scientific Agricultural Research, Damascus, Syria
Corresponding Author: Mahran Zeity

Latakia Center for Scientific Agricultural Research, General Commission for Scientific Agricultural Research,

Damascus, Syria

E-mail: mzma2009@ rmail.com

\section{Cystiphora sonchi (Vallot, 1827), (Cecidomyiidae: Diptera), A new record with annotated checklist of reported cecidomyiid species from Syria}

\author{
Mahran Zeity \\ DOI: https://doi.org/10.33545/27080013.2020.v1.i1a.10
}

\begin{abstract}
Several Sonchus sp. plant samples have been collected from three different localities of Latakia Governorate, Syria during investigation. The samples showed symptoms of Cystiphora sonchi infestation, placed in plastic containers to collect the emerged adults (males and females) in Lab. condition. Emerged adults were mounted in the Hoyer's medium and compared with available literatures. The mounted adults were identified and confirmed to be Cystiphora sonchi. The symptoms and checklist of cecidomyiid species reported so far from Syria has been provided in this study for till date.
\end{abstract}

Keywords: Sonchus sp., gall insect, palearctic realm, Syria

\section{Introduction}

Cecidomyiidae are a large family of Diptera classified with the Bibionomorpha and the Sciaroidea. The family presently contains 6,590 known species belong to 812 genera ${ }^{[1,2]}$. This group of insect is poorly studied in Syria. El-Hariri listed out seven species of Cecidomyiidae from Syria [3], while, Gagné and Jaschhof pointed out that six species are recorded in Syria ${ }^{[1,2]}$. As total, only 12 species (as Resseliella oleisuga was in common between both references) of cecidomyiids were recorded from Syria. The Cystiphora is a small genus of cecidomyiid includes seven species, only one species reported in the Nearctic realm while other is Palearctic species. The genus Cystiphora, is mainly characterized by the induction of galls in species of family Asteraceae, subfamily Cichorieae ${ }^{1}$. Till date, each species of this genus infest a single plant genus ${ }^{[4]}$.Three generations have been recorded for this speices ${ }^{[5,6]}$. Larvae at first is white, later yellowish, cause pustule galls on the leaves of Sonchus oleraceus L. and S. arvensis L. (Asteraceae). Full grown larvae either leave galls and pupate in soil ${ }^{[7]}$, or pupate in the galls ${ }^{8 \& 9}$, the last generation leaves the galls in autumn to hibernate in the soil and next spring; they will pupate and complete their development within several days ${ }^{[10,11]}$. The study was mainly conducted to confirm report the species Cystiphora sonchi from Syria.

\section{Materials and Method}

Several Sonchus sp. plant materials showing galls on leaves were collected during this study. These samples were placed in the bottom of plastic containers for collecting emerged adults. Later, the emerged adults were mounted in the Hoyer's medium for further taxonomic studies. Morphological characters of the studied flies were compared with available literature. Mounted slides were deposited in the collection of Latakia Center for Scientific Agricultural Research.

\subsection{Material Examined}

Five females, two males, ex. Sonchus sp. (Asteraceae), Khirbet Al Jawziyah, Latakia, (N35³9'52"; E 3550'08"; elevation 68 m), June 2019 coll. M. Zeity.

Other collections, symptoms of infestated plants were observed in three other localties Bouka, Latakia (N35³2'12"; E 3548'48"; elevation 45 m, August 2019), Qalaat Mahalibeh, Latakia (N35 30'14"; E 36 05'01"; elevation 653 m, August 2019) and Wadi Al Kars, Latakia (N35³5'04"; E 3607'36"; elevation 514 m, September 2019). 


\section{Results}

\subsection{Taxonomy}

Cystiphora sonchi (Vallot, 1827)

Cecidomyia sonchi Vallot, 1827

Cecidomyia sonchi Bremi, 1847

Cecidomyia sonchi $\mathrm{F}$. Low, 1875

\subsection{Biology of Cystiphora sonchi}

Females of $C$. sonchi lay eggs on the underside of leaves, hatched midges started feeding between upper and lower epidermis. The upper side is slightly raised while the lower side is flat (Fig. 1, 2A-D). Larvae can be seen through the thin membrane of the lower epidermis (Fig. 3, A-B). Feeding of midges cause $3-5 \mathrm{~mm}$ galls dark red in color appears in rows all over the leaves. Number of gall may reach up to 50 for each leaf (Fig.1). The larvae spin a small, whitish cocoon (Fig. 3, C) for pupation. The adult midge breaks the membranous lower, epidermis of the gall and when emerging, pulls the pupal skin partially out of the galls from where it remains protruding (Fig. 3, D, 4, A-D). The adults do not feed.

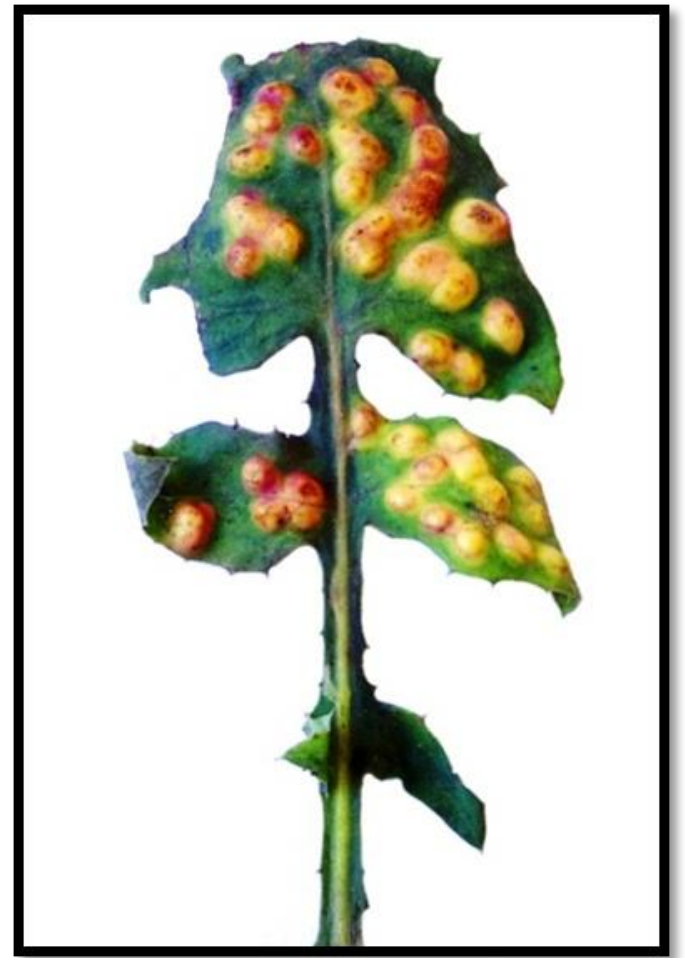

Fig 1: Cystiphora sonchi, gall symptom on the upper side of Sonchus sp. leaf

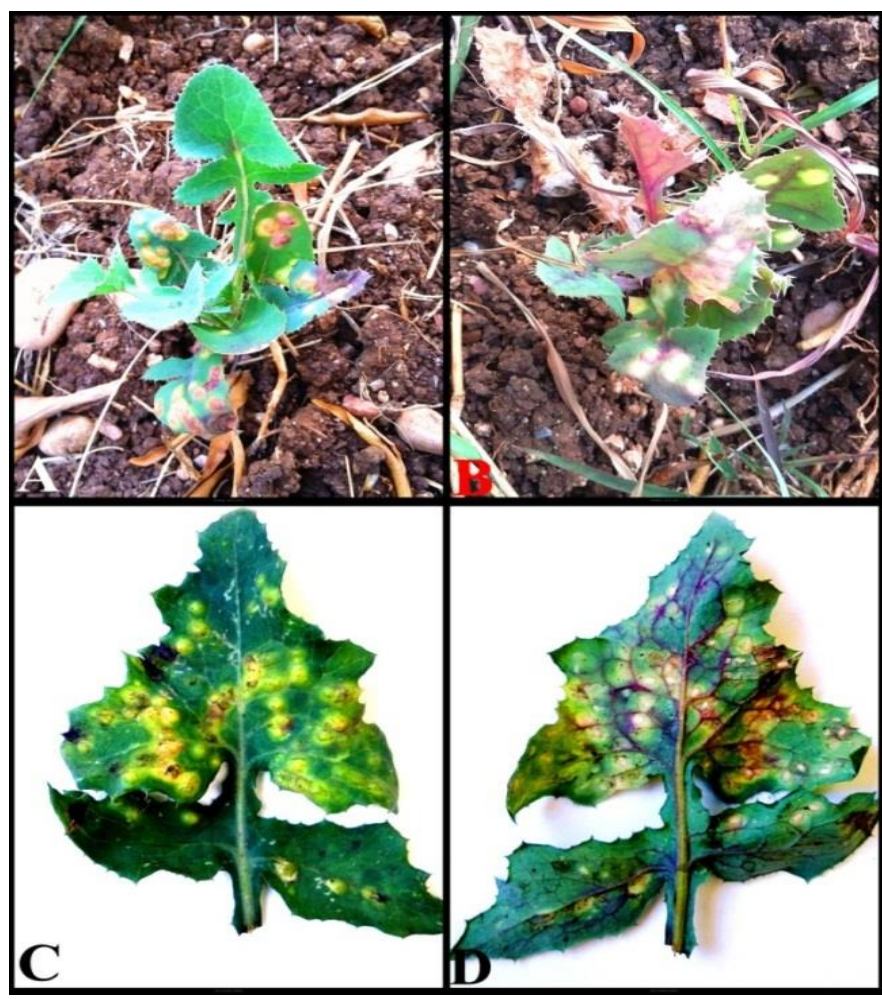

Fig 2: Cystiphora sonchi, A \& B gall symptoms on Sonchus sp.; C upper side of leaf; D. lower side of leaf 


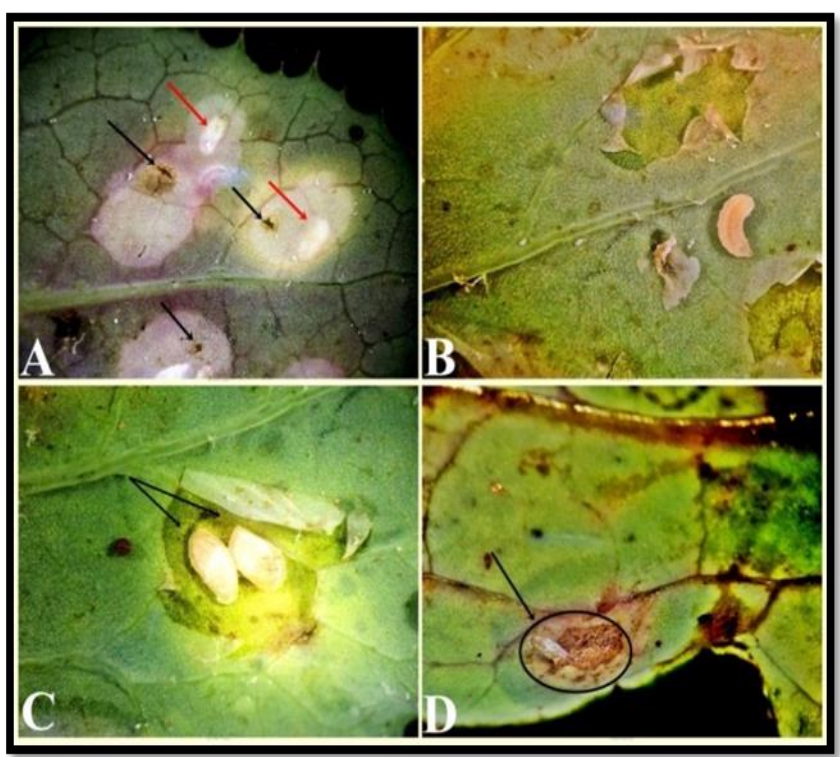

Fig 3: Cystiphora sonchi, A. larvae of midges visible inside the gall (red arowes) emerging by opening (black arowes); B. larva out the gall: C. pupae inside the gall; D. emerging by opening with part of coccon.

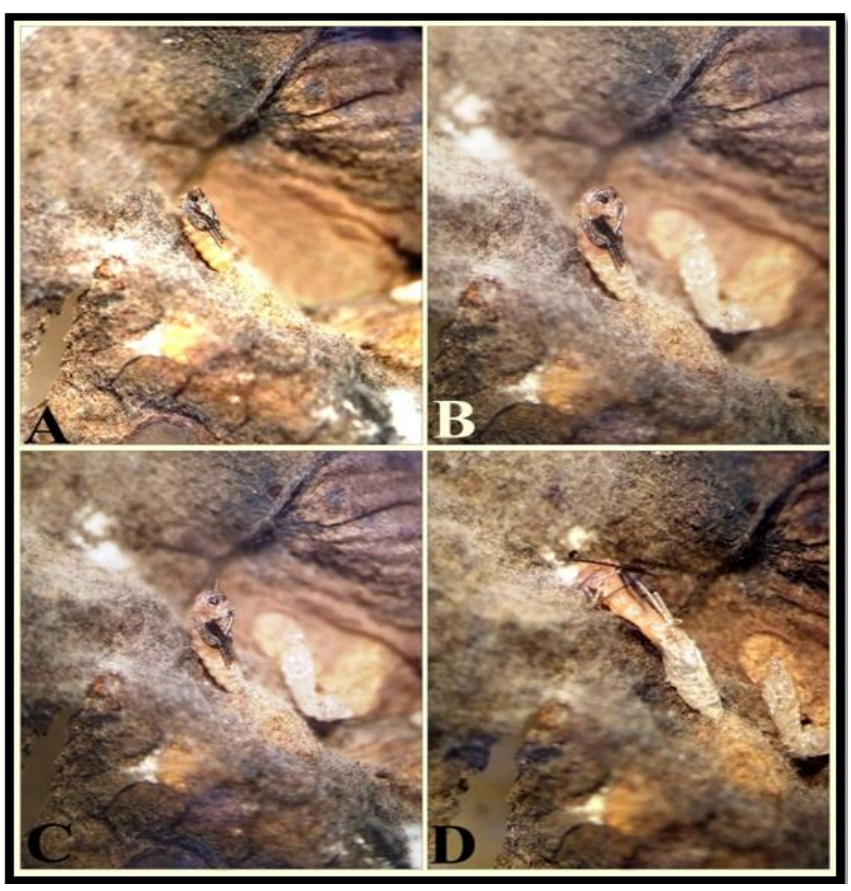

Fig 4: Cystiphora sonchi, A-D emerging steps of adult insect from the coccon of pupa

\subsection{Distribution}

Cystiphora sonchi is distributed all around Europe and West Asia $[11,1,2]$. Recently, this species was reported from Turkey ${ }^{[10]}$, Iran ${ }^{[12]}$ Portugal ${ }^{[13]}$ and the most recent one was from Tunisia [14]. This species was introduced to the Nearctic region (Canada) as biological agent to control $S$. arvensis $^{[6]}$.

3.4 Annotated check list of cecidomyiid species and host plants reported from Syria (Based on El-Hariri ${ }^{[3]}$ and Gagné \& Jaschhof ${ }^{[2]}$

\section{Apiomyia bergenstammi (Wachtl 1882)}

Host plant: Pyrus salicifolia; P. communis (Rosaceae)

Distribution out Syria: Widespread Europe \& Middle East.

\section{Asphondylia anatolica Skuhravá \& Çam, 1998}

Host plant: Astragalus lagopoides (Fabaceae)

Distribution out Syria: Turkey \& Iran.

\section{Baldratia similis Möhn, 1969}

Host plant: Anabasis spp. (Chenopodiaceae)

Distribution out Syria: South West Asia (Iran).

\section{Dasineura affinis (Kieffer, 1886)}

Host plant: Viola silvestris (Violaceae)

Distribution out Syria: Widespread Europe \& aroundMediterranean.

\section{Dasineura oleae (Angelini 1831)}

Host plant: Olea europaea (Oleaceae)

Distribution out Syria: Around-Mediterranean.

\section{Lasioptera berlesiana Paoli, 1907}

Host plant: Olea europaea (Oleaceae)

Distribution out Syria: Around-Mediterranean.

\section{Mayetiola destructor (Say 1817)}

Host plant: Triticum spp. other occasional hosts: Hordeum vulgare, Secale cereale, Elymus sp., Bromus sp. (Poaceae)

Distribution out Syria: Widespread Palearctic, introduced throught to Nearctic \& New Zealand.

\section{Odinadiplosis amygdali (Anagnostopoulos 1929)}

Host plant: Prunus amygdalus (Rosaceae)

Distribution out Syria: Malta, Greece, Turkey, Lebanon \& Afghanistan

\section{Piranea trichatus (Möhn, 1968)}

Host plant: Achillea fragrantissima (Asteraceae)

Distribution out Syria: Only known from Syria (Type locality)

\section{Rabdophaga strobilina (Bremi, 1847)}

Host plant: Salix purpurea; Salix spp. (Salicaceae)

Distribution out Syria: Widespread Palearctic.

\section{Resseliella oleisuga (Targioni-Tozzetti 1887)}

Host plant: Olea europaea (Oleaceae)

Distribution out Syria: Morocco, Italy, Malta, Yugoslavia, Greece \& introduced to Australia.

\section{Stefaniola gloma Möhn, 1971}

Host plant: Caroxylon vermiculatum and Salsola spp. (Chenopodiaceae)

Distribution out Syria: Spain, Algeria, Egypt \& Iraq.

\section{Conclusion}

This study aimed to identifed the insect species induce the galls to the host plant, Sonchus sp. from Syria. Reporting of the species, Cystiphora sonchi is a new record of genus as well as species from Syria. Only twelve species are known prior to this study and further studies regarding cecidomyiid fauna of Syria should be conducted in future.

\section{Acknowledgment}

Author is grateful to the General Commsion for Scientific Agricultural Research (GCSAR), Damascus, Syria for support during this study. 


\section{References}

1. Gagne RJ, Jaschhof M. A Catalog of the Cecidomyiidae (Diptera) of the World. Digital version Entomological Society of Washington, 2014, 493.

2. Gagne RJ, Jaschhof M. A Catalog of the Cecidomyiidae (Diptera) of the World. Digital version Entomological Society of Washington, 2017, 762.

3. El-Hariri G. A List of Recorded Syrian Insect and Acari. Faculty of Agriculture, University of Aleppo, Aleppo, 1968, 160.

4. Caresche LA, Wapshere AJ. The Chondrilla gall midge, Cystiphora schmidti (Robsamen) (Diptera, Cecidomyiidae). II. Biology and host specificity. Bull. Entomol. Res. 1975; 65: 55-64.

5. Skuhrava M and Skuhravy V. Gallmiicken und ihre Gallen auf Wildpflanzen. Ziemsen, Wittenberg Lutherstadt, 1973, 118.

6. Peschken DP, McClay AS, Derby JL and DeClerck R. Cystiphora sonchi (Bremi) (Diptera: Cecidomyiidae), a new biological agent established on the weed perennial sowthistle (Sonchus arvensis L.) (Compositae) in Canada. Canadian Entomologist. 1989; 121:781-791.

7. Skuhravá M and Skuhravy V. Gallmiicken und ihre Gallen auf Wildpflanzen. Ziemsen, Wittenberg Lutherstadt, 1973, 118.

8. Löw F. Üeber einige ungen $\sim$ gend bekannte Cecidomyiden der Wiener Gegend. Verh. Zool.-Bot. Ges., Wien. 1875; 25:13-32.

9. Caresche LA and Wapshere AJ. The Chondrilla gall midge, Cystiphora schmidti (ROBSAMEN) [Diptera, Cecidomyiidae]. II. Biology and host specificity. Bull. EntomoL Res. 1975; 65:55-64.

10. Bayram S, Skuhrava M and Cobanoðlu S. Cystiphora sonchi (Vallot, 1827) and Dasineura gleditchiae (Osten Sacken, 1866) (Diptera: Cecidomyiidae), two new records from Turkey. Turkiye Entomoloji Dergisi. 2005; 29:247-254.

11. Skuhravá M, Skuhravỳ V, Skrzypczyska M, Szadziewski R. Gall midges (Diptera, Cecidomyiidae) of Poland. Annals of the Upper Silesian Museum (Entomology). 2008; 16:5-160.

12. Karimpour Y, Skuhrava M. First record of three species of gall midges (Dip.: Cecidomyiidae) from Iran. Journal of Entomological Society of Iran. 2012; 32(1):137-140.

13. López-Núñez FA, Marchante H, Marchante E. First record of the leaf-gall inductor Cystiphora sonchi (Vallot, 1827) (Diptera: Cecidomyiidae) for Portugal and some notes about its Iberian distribution. Graellsia. 2018; 74(1): e068. http://dx.doi.org/10.3989/graellsia.2018.v74.192

14. Ben Halima Kamel M, Mdellel L, Zouari S, Balmes V. Cystiphora sonchi (Vallot, 1827) (Diptera: Cecidomyiidae), first record for Tunisia and Africa, Bulletin OEPP/EPPO Bulletin. 2019; 49(3):597-598. 